\title{
The Plate Objective Scoring Tool (POST): Further Reflections and Extended Applications
}

\author{
Tariq $\bigcirc$ Abbas $\mathbb{D}^{1-4}$ \\ 'Pediatric Urology Section, Sidra \\ Medicine, Doha, Qatar; ${ }^{2}$ College of \\ Medicine, Qatar University, Doha, Qatar; \\ ${ }^{3}$ Weill Cornell Medicine Qatar, Doha, \\ Qatar; ${ }^{4}$ Regenerative Medicine Research \\ Group, Department of Health Science \\ and Technology, Aalborg University, \\ Aalborg, Denmark
}

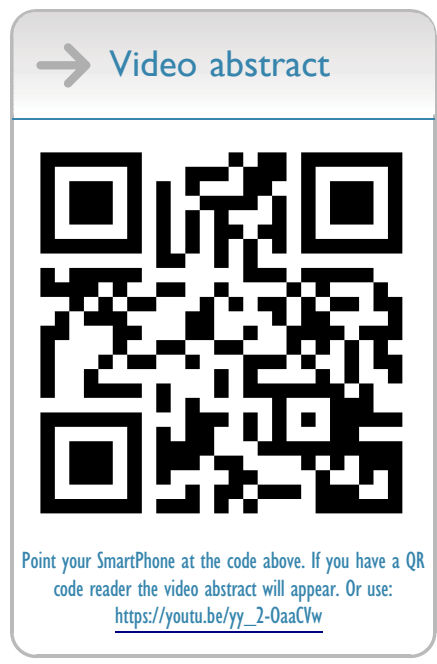

Correspondence: Tariq O Abbas Email tabbas@sidra.org; tariq2c@hotmail.com

\begin{abstract}
Hypospadias is a common birth defect of the male external genitalia. However, there are conflicting arguments about the optimal classification approach and ideal surgical technique. We have introduced the Plate Objective Scoring Tool (POST) to define critical glanular phenotypic landmarks of the urethral plate. We propose that POST can objectively, reproducibly, and accurately determine urethral plate quality, thus permitting robust comparison between the different surgical techniques commonly utilized in hypospadias repair. Furthermore, the POST scoring system represents a versatile tool that can objectively quantify key variables in hypospadiology that are currently not well defined. Further validation of POST should lead to better identification and management of postoperative complications.
\end{abstract}

Keywords: hypospadias, scoring tool, classification, POST, objective

\section{Introduction}

Hypospadias is considered a common birth defect of the external genitalia of boys. ${ }^{1,2}$ However, several controversies surround the different classification approaches and ideal surgical techniques for correction. ${ }^{3}$ We have introduced the Plate Objective Scoring Tool (POST) to define critical phenotypic landmarks of the urethral plate (UP) within the glans. POST allows objective and reproducible determination of urethral plate quality, thereby enabling comparison of the different surgical techniques commonly used for hypospadias repair. ${ }^{4,5}$ The POST system originated from studying the normal configuration of the glans in children who were anesthetized for ritual circumcision, ${ }^{6}$ leading to the determination of three key anatomical landmarks: A, B, and $\mathrm{C}$ (Figure 1). The area from A to B is the extent of the neo-meatal opening, while $\mathrm{B}$ to $\mathrm{C}$ is the extent of the vertical glanular fusion line. Having identified these reference points, the ratio $(\mathrm{AB}) /(\mathrm{BC})$ defines POST value, which represents urethral impression within the glans penis and thus overall quality of the urethral plate.

\section{Embryological Basis of POST}

The rationale behind POST scoring is well supported by a robust embryological evidence base. Developmentally, the opening zipper hypothesis begins with gradual canalization of the solid urethral plate within the penile shaft and glans to form the urethral groove, while the closing zipper depends on fusion of the urethral layers to form the final urethral tube. $^{7}$ Therefore, a shorter (AB) length is explained by arrest of the ventro-dorsal canalization process within the glans penis around gestational week 14. As a result, lower $\mathrm{AB} / \mathrm{BC}$ ratio could represent an earlier stage of urethral development and thus more severe phenotypical stages. 


\section{Graphical Abstract}

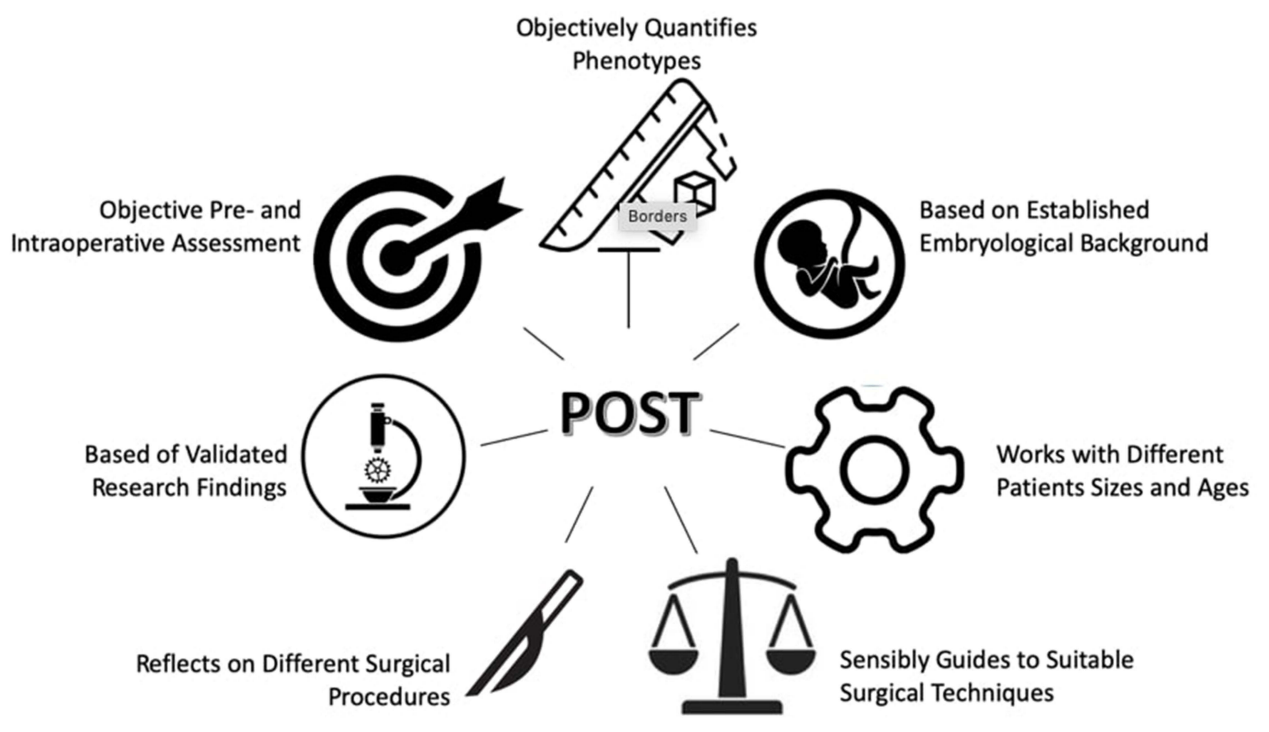

\section{An Aid for Objective Preoperative Assessment and Parental \\ Counseling}

It is important to use both standardized assessment tools and measures of penile anthropometric variables, including patient age and erection status. ${ }^{8,9}$ Walid et al noted that urethral plate width increases with age, making definitive cut-off values unsuitable for defining a favorable urethral plate. ${ }^{10}$ POST instead permits objective measurement of hypospadias severity, and urethral plate quality in particular, prior to complete physiological retraction of the prepuce (Figure 2), but without significant influence of patient age on assessment outcome. Therefore, the POST system can be used in outpatient clinics to help surgeons guide decision-making objectively, inform surgical planning, and assist with appropriate parent counselling.

\section{Correlates of Favorable Urethral Plate Quality}

Defining a favorable urethral plate is considered an essential task but is nonetheless difficult to quantify objectively. ${ }^{5}$ For this purpose, the $\mathrm{G}$ component of the GMS score ${ }^{11}$ was introduced, and both G1 and G2 can be clustered in the favorable category. We have observed excellent correlation between POST score $(>1.2)$ and $(\mathrm{G} 1$, G2) across several pediatric urologists. (Figure 3) We also obtained high intra-rater agreement by Inter-Class Correlation (ICC) analysis. ${ }^{4}$

\section{Standardizing Diagnosis of Meatal Stenosis}

Approximately $20 \%$ of circumcised boys have a meatal diameter less than $5 \mathrm{Fr}$ between the ages of 5 and 10 years. ${ }^{12}$ Diagnosis of meatal stenosis is highly subjective and is essentially defined as "change in the elliptical to a circular shape secondary to fibrosis or scarring, with visually apparent narrowing". ${ }^{13}$ POST scoring can help to objectively diagnose meatal stenosis, which should be considered if the ventral membranous lip of the meatus is situated beyond point B (Figure 4).

\section{Megameatus Intact Prepuce Variant - NOT an Exception!}

Bhat et al stated that

The anatomic characteristics of the megameatus intact prepuce (MIP) hypospadias variant present a unique challenge to surgeons. The dissection of the wide meatus and urethral plate may result in thin glanular wings that are more prone to dehiscence and urethral fistula formation. ${ }^{14}$

It has since been hypothesized that the embryological development of the urethra results from 3D progression of the urethral plate from proximal to distal in the penis, which proceeds in synchrony with axial ventralto-dorsal groove development within the glans. This theory is consistent with several variants and anatomical findings over the spectrum of hypospadias 


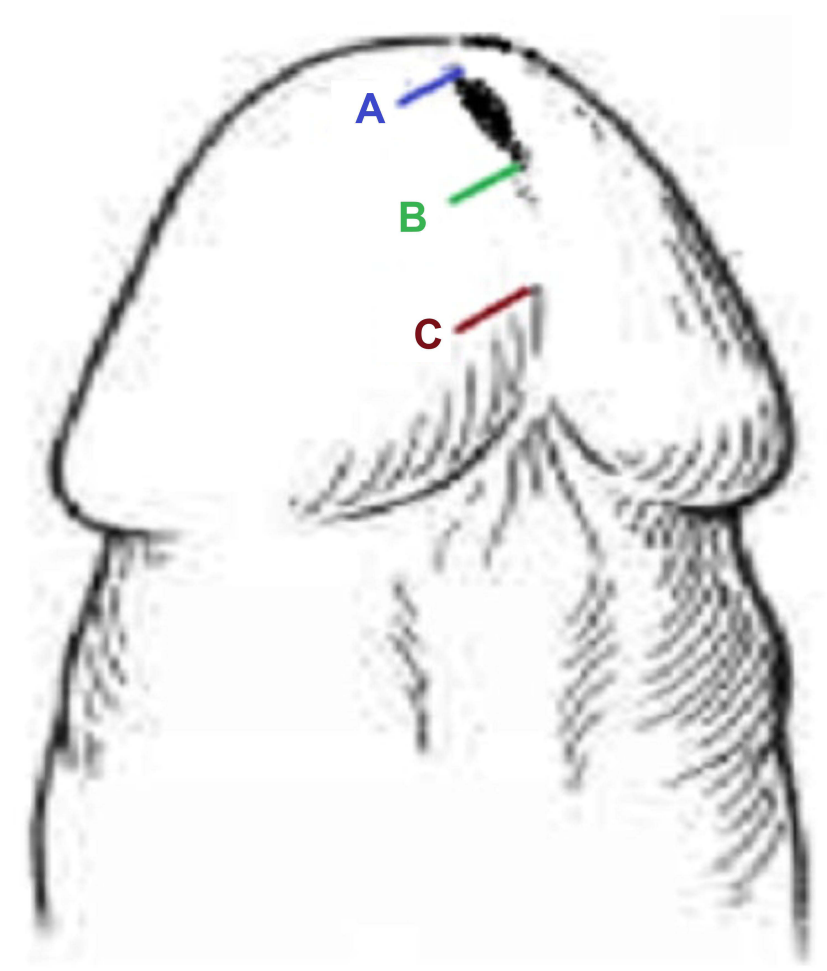

Figure I An illustration showing typical anatomical glanular landmarks. Point $(A)$ is the distal extent of the meatal opening, point (B) is the proximal extent of the meatal opening and distal limit of the glanuar closure line, and point $(C)$ is the proximal limit of the glanular closure line.

Notes: Adapted with modifications from: Abbas TO, Ali M. Urethral Meatus and Glanular Closure Line: Normal Biometrics and Clinical Significance. Urol J. 2018;15:277-279. https://doi.org// 0.22037/uj.v0i0.4402. ${ }^{6}$ CC BY license.

phenotypes and how these align with POST score. However, the MIP variant does not follow this embryological pattern. It has been hypothesized that MIP results from over canalization of the glans urethra, or alternatively from compression and ischemic necrosis after the development of the distal urethra. However, we have observed that almost all cases of MIP have unfavorable POST score that might reflect an underdevelopment of the spongiosal envelope of the glanular and distal penile urethra (Figure 5).

\section{Reflections on Tubularized Incised Plate Urethroplasty from a POST Point-of-View}

Tubularized Incised Plate (TIP) urethroplasty was popularized by Snodgrass in 1994 and has since become very common. ${ }^{15}$ This surgical technique depends on a midline relaxing incision of the urethral plate to allow a urethroplasty without tension. Snodgrass suggested incising the urethral plate deeply enough to reach the corpora, and then extending from the hypospadiac meatus proximally to reach the mucocutaneous junction distally. (Figure 6A and B). To diminish risk of meatal stenosis, Snodgrass suggested a modification of TIP where the starting distal point for tubularization of the neo-urethra commences $\sim 3 \mathrm{~mm}$ below the edge of the urethral plate, which is approximately at the level of the "midglans". ${ }^{16}$ This can be interpreted as an attempt to increase the (neo$\mathrm{AB}$ ) distance to achieve an adequate $\mathrm{AB} / \mathrm{BC}$ (POST) ratio. (Figure 7) However, this also results in higher chance of (ventral) glanular meatus, which is considered

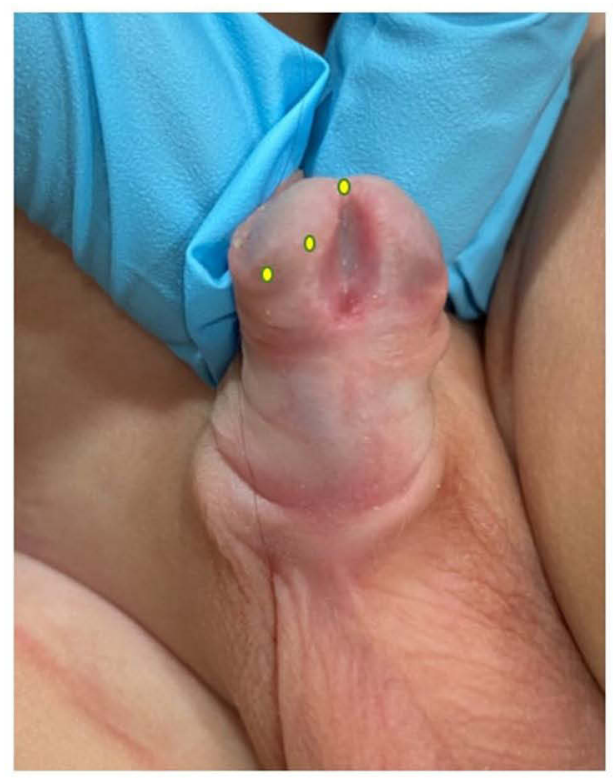

Figure 2 Two infant male patients with coronal hypospadias and POST landmarks that could potentially be marked during outpatient visits before complete retraction of the foreskin. 


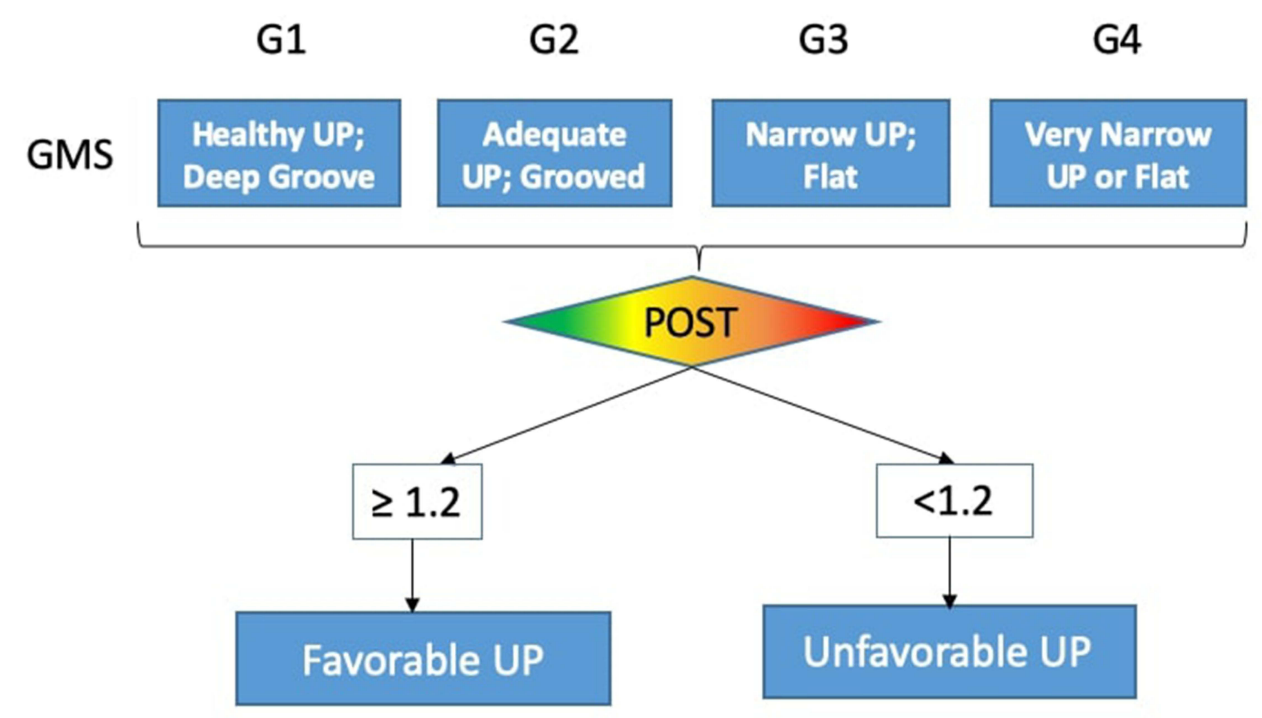

Figure 3 Correlation between GMS and POST scores.

a suboptimal result in hypospadias reconstructive surgery. On the other hand, in cases where the urethral plate is unfavorable ${ }^{4}(\mathrm{AB}<\mathrm{BC})$, this approach could potentially lead to a higher risk of meatal stenosis. (Figure 6B)

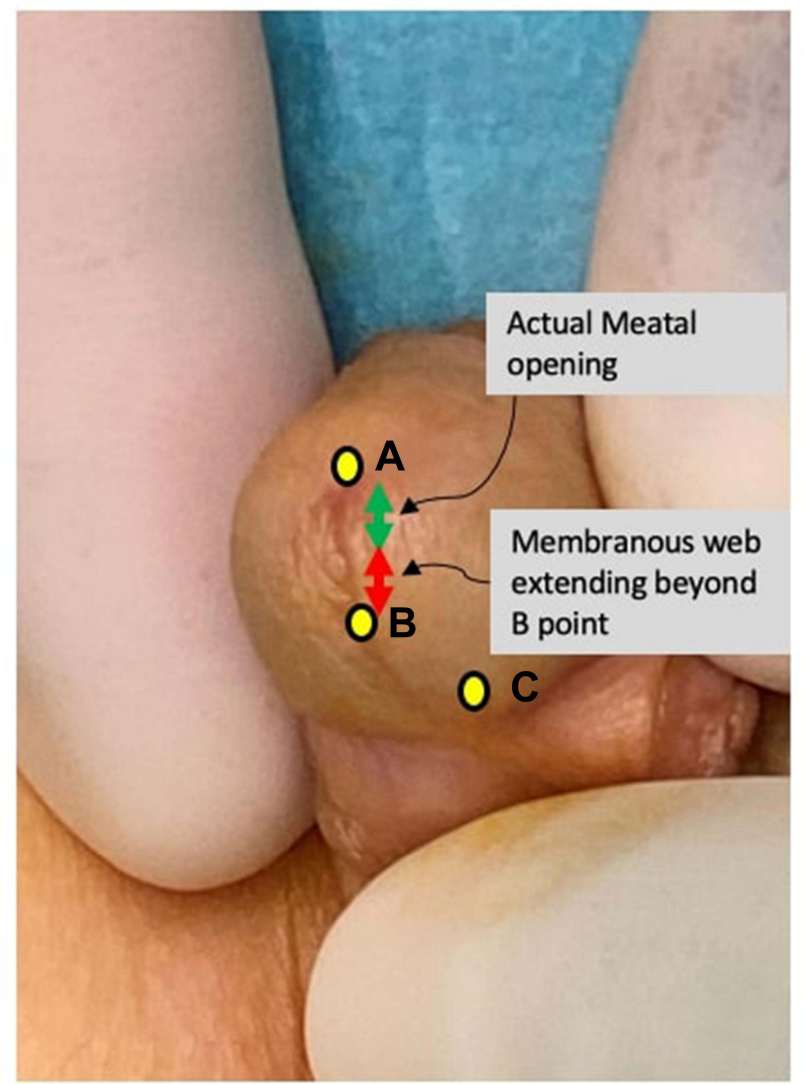

Figure 4 Spectrum of meatal stenosis as defined according to POST. A ventral lip of a membranous web extends distal from $B$ towards point $A$.
Likewise, Mane et al have gone further by defining the distal extent of the neourethral tube as $\sim 5 \mathrm{~mm}$ from the edge of the urethral plate. ${ }^{17}$ At the same time, Mane recommended not extending the midline relaxing incision of the urethral plate to the "tip of the urethra" distally.

\section{Reflections on Dorsal Inlay Grafted TIP from a POST Point-of-View}

In cases of unfavorable POST, a logical approach is to increase the $\mathrm{AB} / \mathrm{BC}$ ratio by incising the glans distal to the mucocutaneous junction, thereby advancing the A (neo-A) point. This would result in a raw, wounded area within the glans beyond the urethral plate territory and mandates grafting of the incised area to prevent meatal stenosis (ie dorsal inlay grafted TIP [D-TIP]). ${ }^{18,19}$ (Figure 8) However, it is important not to overshoot the incision within the glans and thus create an epispadiac meatus. The POST formula can further help define distal extent of the midline incision (the neo-A point) when performing dorsal inlay TIP (Figure 9).

\section{Defining Lateral Borders of the Urethral Plate During Second-Stage Urethroplasty}

During second-stage urethroplasty, it is considered essential to reconstruct a "wide enough" neo-urethral tube to match glans size and thus avoid distal urethral narrowing and subsequent urethrocutaneous fistulas. ${ }^{20}$ It is also crucial to objectively define the minimum 

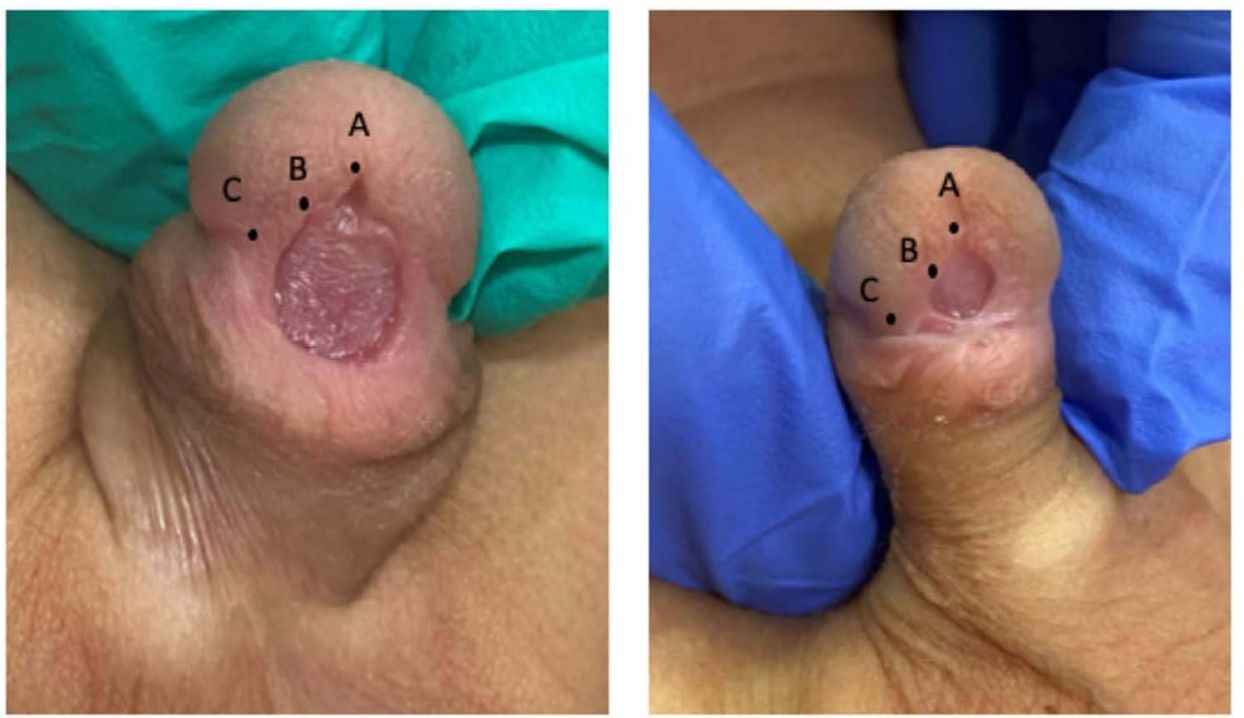

Figure 5 MIP cases demonstrating unfavorable POST scores.
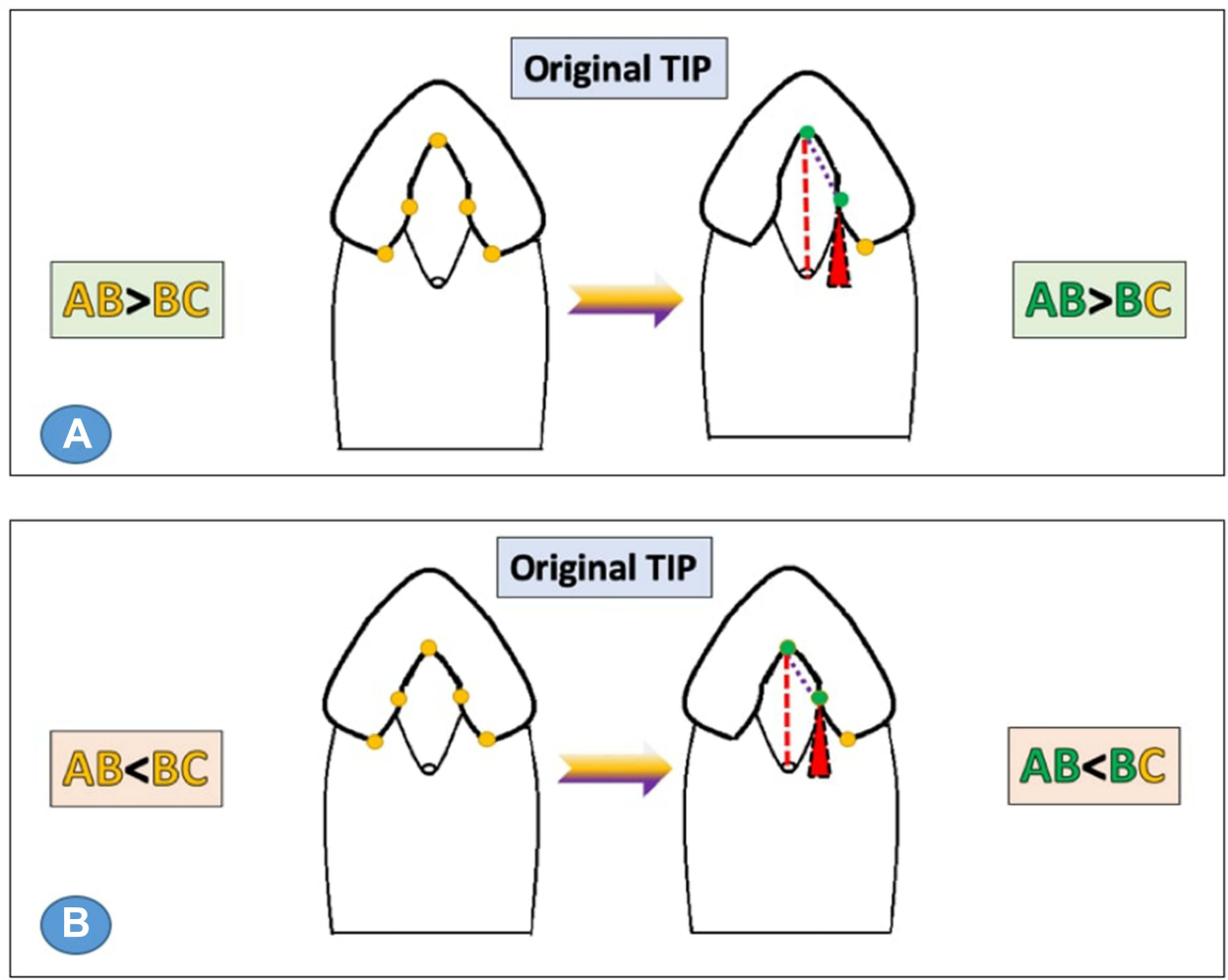

Figure 6 Illustration of POST landmarks in cases of TIP repair. (A) in cases of favorable POST, TIP would result in a wide meatal opening (neo-AB) that is larger than the potential glanular fusion line (neo-BC). (B) In cases of unfavorable POST, TIP would result in a meatal opening (neo-AB) that is smaller than the potential glanular fusion line (neo-BC) and thus confer risk of stenosis.

amount of skin/graft strip required to construct the neourethra, in order to achieve a more consistent surgical description with higher reproducibility (while also reducing risk of Balanitis Xerotica Obliterans [BXO] due to inclusion of unneeded hair-bearing skin). We currently base our demarcation of the two lateral borders of the urethral plate to be tubularized, formed by parallel lines crossing the two B points at the level of the widely split glans and extending proximally to the level of the meatus Figure 10. 


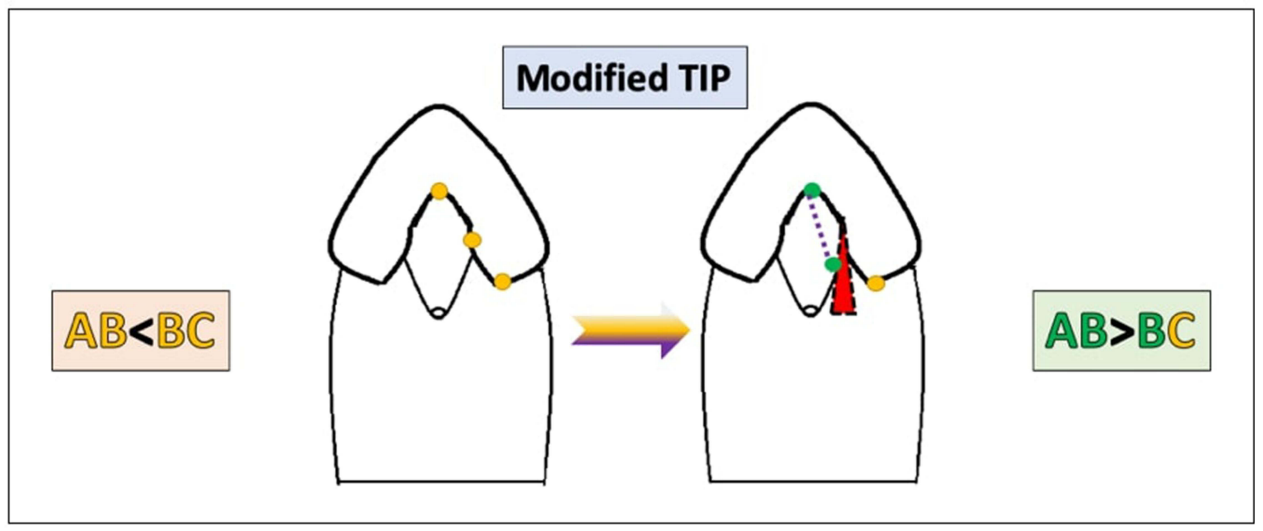

Figure 7 Modified TIP would result in a wide meatal opening (neo-AB) larger than the potential glanular fusion line (neo-BC). The distal extent of the urethroplasty (neo-B point) starts $\sim 3 \mathrm{~mm}$ below the tip of the paraurethral incision line.

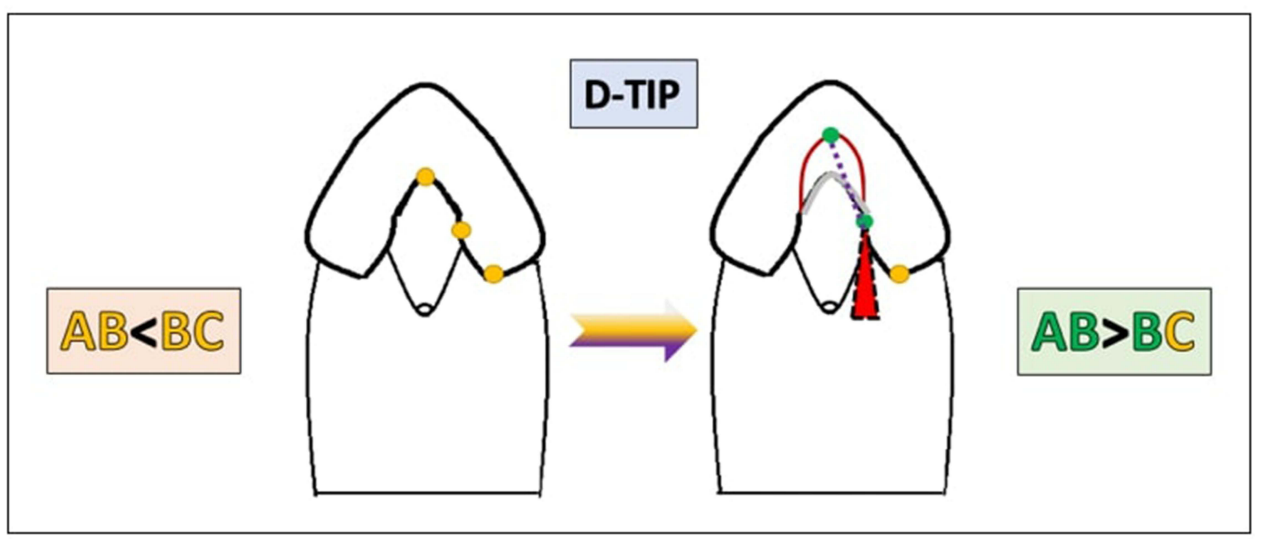

Figure 8 D-TIP would result in a wide meatal opening (neo-AB) by incising the glans distal to the mucocutaneous junction larger than the potential glanular fusion line (BC).
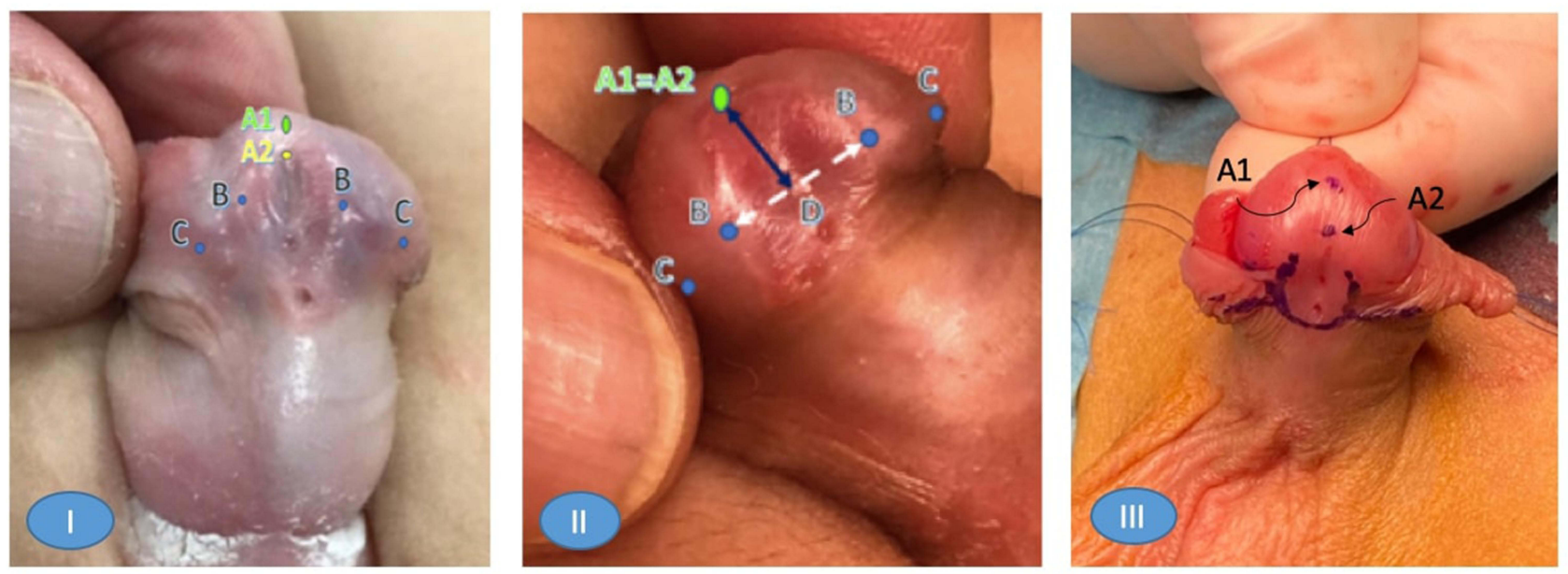

Figure 9 (I) In cases of unfavorable POST $(A B \leq B C)$, the distal end of the urethral plate mucocutaneous junction (A2) marks the limit of the incision in TIP urethroplasty. Therefore, (A2-B) will be almost equal to (B-C), putting the risk of stenosis on the neomeataus in this situation. On the other hand, extending the incision distally to (AI) as objectively determined by $(A I-B=1.2 \times B C)$ will avoid this risk, and grafting will be advisable in this instance. (II) In cases of favorable POST, the distal end of the urethral plate ends at the point $(A I=A 2)$ where $(A I-B>I .2 \times B-C)$ and incision distal to the mucocutaneous junction would not be needed. (III) Marking of both $A I$ and $A 2$ at the beginning of surgery in cases of unfavorable UP. 


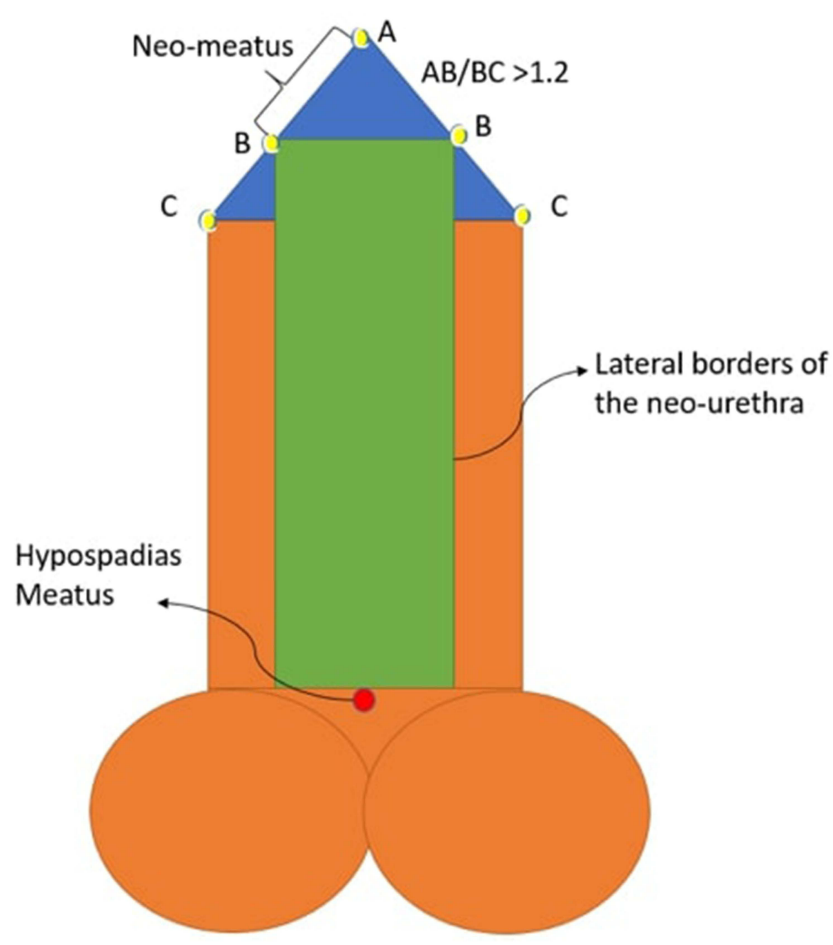

Figure 10 An illustration demonstrating POST landmark application to define the main borders of the neourethra during second-stage hypospadias repair.

\section{Standardization of Urethral Hypoplasia Extent Measurements}

POST scoring can directly record the quality of the distal urethral plate as well as the extent of urethral development. Building on this hypothesis, we used a POST-based approach to explore the extent of the hypoplastic urethra, defined by the distance between B points and the divarication of the spongiosa (Figure 11). We observed that unfavorable UP correlated with longer hypoplastic urethra that matched the underdeveloped urethra (unpublished data). This is yet another finding that supports POST as an objective and reliable measure of urethral plate quality and under-development of the urethra. However, it is important to note how spongiosum development can affect POST scoring, since surprisingly low values may be calculated in MIP cases where the urethra is not supported by well-developed spongiosum (unlike distal hypospadias). (Figure 12) A cytokeratin-based experiment ${ }^{21}$ revealed that the UP extends from an endodermal origin near the bladder all the way to the distal tip of the urethral meatus, rather than having an ectodermal invagination contributing to the glanular urethra. This further supports the concept that POST is well-aligned with proximal-distal development of the UP and surrounding spongiosa. Baskin et al stated that

From a broader perspective, the fusion process during formation of the human penile urethra (within the shaft) consists of three separate fusion events: (a) Epidermal fusion completes the ventral penile skin. (b) Endodermal fusion forms the penile urethra. (c) Finally, upon removal of the midline epithelial seam, a right-left mesenchymal confluence is established ventral to the forming urethra. ${ }^{22}$

In most circumstances, the magnitude of urethral hypoplasia correlates with urethroplasty length. It has also been shown that the longer the urethral defect, the greater the risk of repair failure, which can make restoration of the corpus spongiosum far more difficult. ${ }^{23}$

\section{Conclusion}

The POST scoring system represents a versatile tool for objectively quantifying several critical variables in

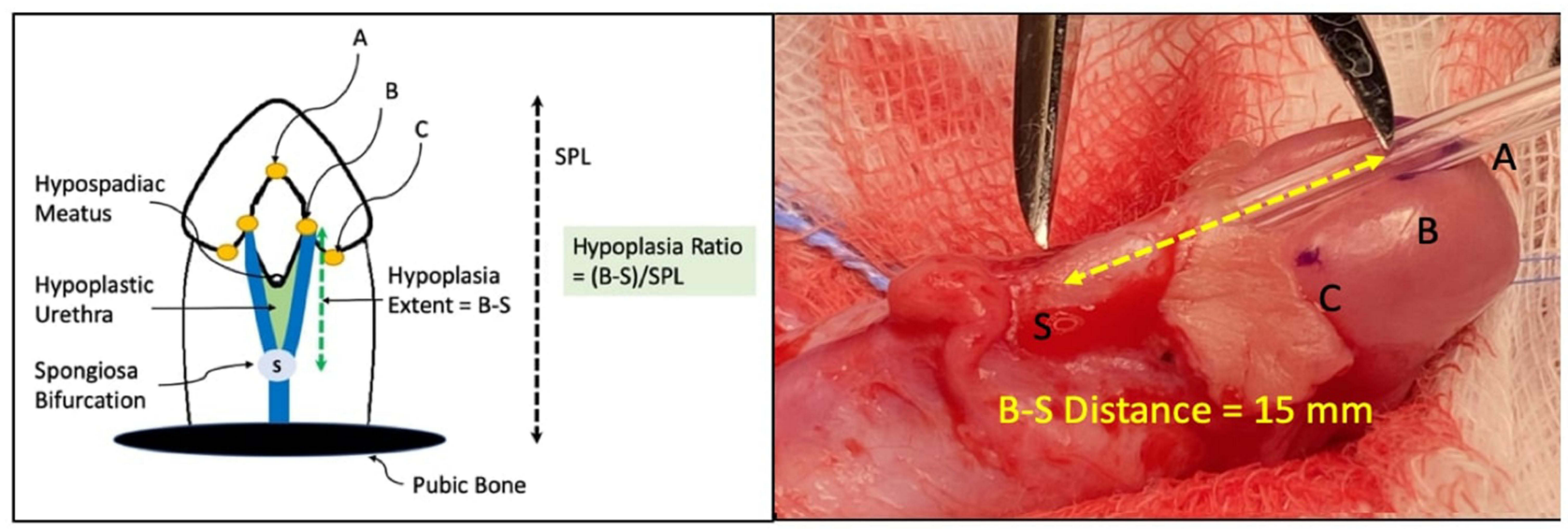

Figure I I Standardization of the measurement of hypoplasia extent from (B) points to the bifurcation of the spongiosa divided by the stretched penile length (SPL). 


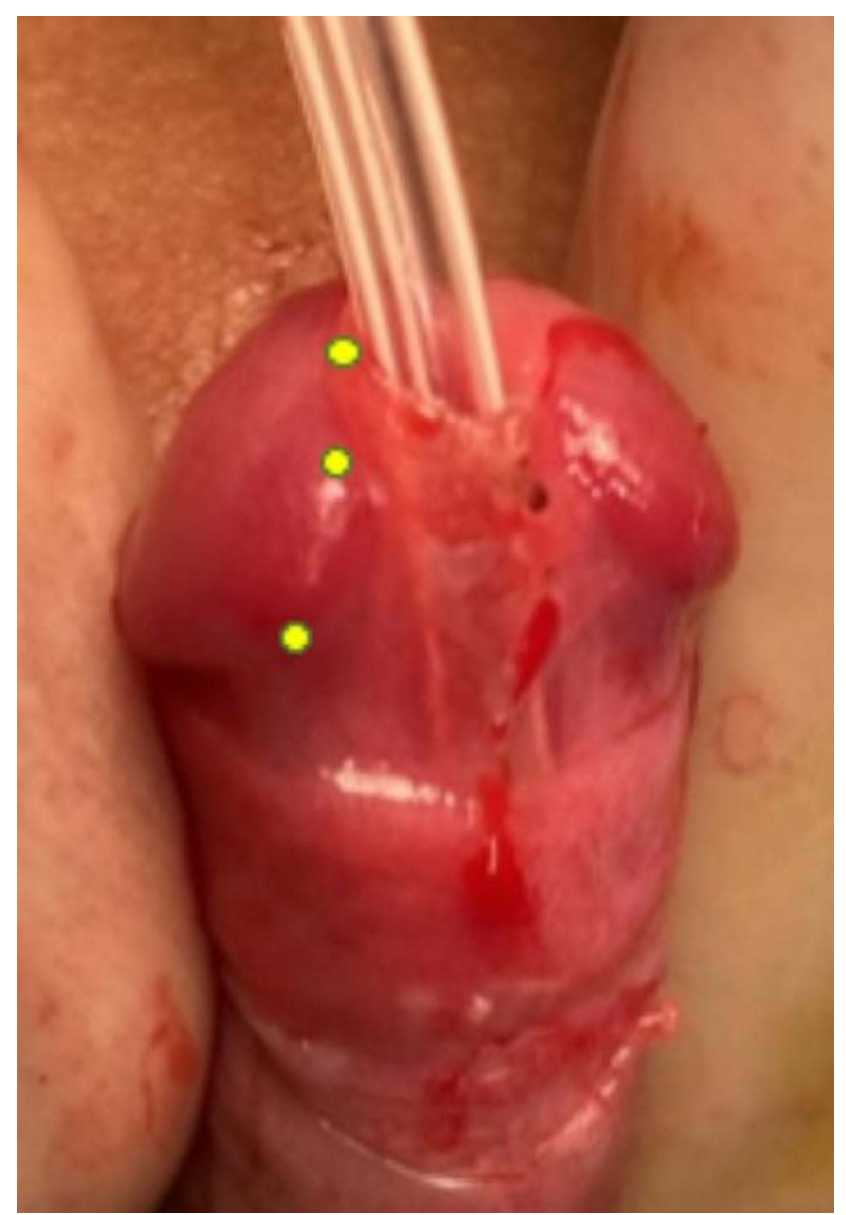

Figure 12 POST can reflect spongiosa development of the distal urethra. Although the meatus (end of the urethral opening) is at the tip of the glans penis, this patient has a low POST and thus a hypoplastic distal urethra.

hypospadiology that are presently not well defined. Further validation of POST will be essential to better correlate preoperative assessments with postoperative complications, and thereby define key risk factors more consistently and reproducibly.

\section{Disclosure}

The author declares no conflicts of interest for this work.

\section{References}

1. McCarthy L, Abbas T. Hypospadias - repair of distal hypospadias. BJU Int. 2020. doi:10.18591/BJUIK.0624

2. Abbas T, McCarthy L. Foreskin and penile problems in childhood. Surg. 2016;34. doi:10.1016/j.mpsur.2016.03.007

3. Tariq Abbas LM. Hypospadias: classification and standardisation of terminology. BJU Int. 2018. doi:10.18591/BJUIK.0623
4. Abbas TO, Vallasciani S, Elawad A, et al. Plate Objective Scoring Tool (POST); An objective methodology for the assessment of urethral plate in distal hypospadias. J Pediatr Urol. 2020;16:675-682. doi:10.1016/j.jpurol.2020.07.043

5. Abbas TO, Braga LH, Spinoit AF, Salle JP. Urethral plate quality assessment and its impact on hypospadias repair outcomes: a systematic review and quality assessment. $J$ Pediatr Urol. 2021;17(3):316-325. doi:10.1016/j.jpurol.2021.02.017

6. Abbas TO, Ali M. Urethral meatus and glanular closure line: normal biometrics and clinical significance. Urol J. 2018;15:277-279. doi:10.22037/uj.v0i0.4402

7. Li Y, Sinclair A, Cao M, et al. Canalization of the urethral plate precedes fusion of the urethral folds during male penile urethral development: the double zipper hypothesis. $J$ Urol. 2015;193:1353-1360. doi:10.1016/j.juro.2014.09.108

8. Kamel I, Gadalla A, Ghanem H, Oraby M. Comparing penile measurements in normal and erectile dysfunction subjects. J Sex Med. 2009;6(8):2305-2310. doi:10.1111/j.1743-6109.2009.01305.x

9. Greenstein A, Dekalo S, Chen J. Penile size in adult men-recommendations for clinical and research measurements. Int J Impot Res. 2020;32(2):153-158. doi:10.1038/s41443-019-0157-4

10. Walid A, Minhajuddin S, Rajib K, et al. Tabularised Incised Plate (TIP) urethroplasty in narrow V/S wide urethral plate: a comparative study in a developing country perspective. Arch Pediatr Surg. 2021;5. doi: $10.36959 / 472 / 360$

11. Merriman LS, Arlen AM, Broecker BH, Smith EA, Kirsch AJ, Elmore JM. The GMS hypospadias score: assessment of inter-observer reliability and correlation with post-operative complications. $J$ Pediatr Urol. 2013;9:707-712. doi:10.1016/j.jpurol.2013.04.006

12. Joudi M, Fathi M, Hiradfar M. Incidence of asymptomatic meatal stenosis in children following neonatal circumcision. $J$ Pediatr Urol. 2011;7:526-528. doi:10.1016/j.jpurol.2010.08.005

13. Morris BJ, Moreton S, Krieger JN. Meatal stenosis: getting the diagnosis right. Res Rep Urol. 2018;10:237-239. doi:10.2147/RRU. S192310

14. Bhat A, Bhat M, Bhat A, Singh V. Results of tubularized urethral plate urethroplasty in megameatus intact prepuce. Indian $J$ Urol. 2017;33:315-318. doi:10.4103/iju.IJU_361_16

15. Snodgrass W. Tubularized, incised plate urethroplasty for distal hypospadias. J Urol. 1994;151:464-465. doi:10.1016/S0022-5347(17) 34991-1

16. Snodgrass WT. Utilization of urethral plate in hypospadias surgery. Indian J Urol. 2008;24(2):195. doi:10.4103/0970-1591.40615

17. Mane S, Arlikar J, Dhende N. Modified tubularized incised plate urethroplasty. $J$ Indian Assoc Pediatr Surg. 2013;18:62. doi:10.4103/0971-9261.109354

18. Abbas TO, Pippi Salle JL. When to graft the incised plate during TIP repair? A suggested algorithm that may help in the decision-making process. Front Pediatr. 2018;6:326. doi:10.3389/fped.2018.00326

19. Abbas TO, Ali TA, Uddin S. Urine as a main effector in urological tissue engineering - a double-edged sword. Cells. 2020;9(3):538. doi: $10.3390 /$ cells 9030538

20. Bracka A. The role of two-stage repair in modern hypospadiology. Indian J Urol. 2008;24(2):210-218. doi:10.4103/0970-1591.40618

21. Kurzrock EA, Baskin LS, Cunha GR. Ontogeny of the male urethra: theory of endodermal differentiation. Differentiation. 1999;64. doi:10.1046/J.1432-0436.1999.6420115.X

22. Baskin L, Shen J, Sinclair A, et al. Development of the human penis and clitoris. Differentiation. 2018;103:74-85. doi:10.1016/j.diff.2018.08.001

23. Breyer BN, McAninch JW, Whitson JM, et al. Multivariate analysis of risk factors for long-term urethroplasty outcome. J Urol. 2010;183. doi:10.1016/J.JURO.2009.10.018 


\section{Publish your work in this journal}

Research and Reports in Urology is an international, peer-reviewed, open access journal publishing original research, reports, editorials, reviews and commentaries on all aspects of adult and pediatric urology in the clinic and laboratory including the following topics: Pathology, pathophysiology of urological disease; Investigation and treatment of urological disease; Pharmacology of drugs used for the treatment of urological disease. The manuscript management system is completely online and includes a very quick and fair peer-review system, which is all easy to use. Visit http://www.dovepress.com/ testimonials.php to read real quotes from published authors.

Submit your manuscript here: https://www.dovepress.com/research-and-reports-in-urology-journal 